\title{
Negative Attribution Bias and Anger after Traumatic Brain Injury
}

\author{
Dawn Neumann, PhD \\ Assistant Research Professor \\ Indiana University School of Medicine, Department of Physical Medicine and Rehabilitation \\ Rehabilitation Hospital of Indiana \\ 4141 Shore Drive \\ Indianapolis, IN 46254 \\ Email: dmneuman@iupui.edu \\ Phone: 317-329-2188 \\ Corresponding author \\ James F. Malec, PhD \\ Professor and Research Director, Indiana University School of Medicine, Department of Physical Medicine \\ and Rehabilitation \\ Rehabilitation Hospital of Indiana \\ Indianapolis, IN
}

Flora M. Hammond, MD

Professor and Department Chair, Indiana University School of Medicine, Department of Physical Medicine and Rehabilitation

Chief of Medical Affairs, Rehabilitation Hospital of Indiana

Indianapolis, IN

This research was funded by the National Institute on Disability, Independent Living, and Rehabilitation Research (NIDILRR) Switzer Research Fellowships Program Priority (CFDA No. 84.133F-1); the Indiana Spinal Cord and Brain Injury Research Fund; and the Indiana University Brain Rehabilitation, Advanced Imaging, and Neuroscience (BRAIN) Signature Center Initiative.

Conflicts of interest: Dr. Dawn Neumann is a small business owner that currently receives federal grant funding from the National Institutes of Health, NICHD STTR (grant \# 1R41HD077967-01A1), to develop and investigate an intervention to improve emotional processing after brain. For the remaining authors, no other conflicts of interest are declared.

Reprint requests to Dawn Neumann, PhD

Number of Words: 3,378 (4500 max)

Key Words: Brain Injury, Emotion, Anger, Aggression, Attributions

This is the author's manuscript of the article published in final edited form as:

Neumann, D., Malec, J. F., \& Hammond, F. M. (2017). Negative Attribution Bias and Anger After Traumatic Brain Injury.

Journal of Head Trauma Rehabilitation, 32(3), 197-204. https://doi.org/10.1097/HTR.0000000000000259 


\begin{abstract}
Objectives: . To compare negative attributions (i.e., judgments made about intent, hostility and blame regarding others' behaviors) made by people with and without TBI, and to examine the degree to which these predict angry ratings in response to situations.

Setting: Outpatient rehabilitation hospital.

Participants: Forty-six adults with moderate to severe TBI and 49 healthy controls (HC).

Design: Cross-sectional study using a quasi-experimental research design.

Main Measures: Responding to hypothetical scenarios, participants rated how irritated and angry they would be, and how intentional, hostile and blameworthy they perceived characters' behaviors. Three scenario types differentiated by the portrayal of characters’ actions: benign, ambiguous, or hostile. All scenarios theoretically resulted in unpleasant outcomes for participants.

Results: Participants with TBI had significantly higher ratings for feeling 'irritated' and 'angry', and attributions of ‘intent', 'hostility’, and 'blame’ than HC’s for all scenario types. Negative attribution ratings accounted for $72.4 \%$ and $65.3 \%$ of the anger rating variance for participants with and without TBI, respectively.

Conclusion: People with TBI may have negative attribution bias, in which they disproportionately judge the intent, hostility, and blameworthiness of others' behaviors. These attributions contributed to their ratings of feeling angry. Individuals with TBI who have anger problems should be evaluated for this bias, and anger treatments could aim to alter negative attributions. However, before implementing clinical practice changes, there is a need for replication with larger samples, and further investigation of the characteristics associated with negative attribution bias.
\end{abstract}


Problems with anger are quite typical after traumatic brain injury (TBI). ${ }^{1-5}$ Moreover, these problems differ from those of healthy controls in terms of severity and prevalence. A recent study revealed that people with TBI have elevated levels of anger compared to healthy controls. In addition, a significantly higher percentage of people with TBI are classified as having “above average” anger (42\% vs 20\%) and hostility (48\% vs 20\%). ${ }^{6}$ It is important to determine the causes of anger after TBI so that behavioral treatments can be designed to address the origins of the problem. The bulk of what little research has been conducted to date focused on understanding the fundamentals of aggression after TBI, rather than anger in particular. These studies found that aggression is correlated with factors such as depression, alexithymia, cognition, alcohol and substance abuse, socio-economic status, and pre-morbid aggression. ${ }^{7-10}$ While these findings are informative, there are two main limitations. First, these studies evaluated aggression as a trait (behavior over time) rather than a response to a particular situation. Understanding the context in which anger or aggression occurs is critical to pinpointing specific contributors to the problem. Second, there is a significant distinction between anger and aggression that should not be overlooked. Aggression is a behavioral response that is often driven by anger, an emotion. ${ }^{11}$ Consequently, it is important to recognize and target factors that contribute to anger in order to reduce subsequent expressions of aggression.

In an attempt to better understand the causes of anger after TBI, we recently measured anger in response to particular situations. ${ }^{3}$ In that study we tested the hypothesis that participants’ ratings of how irritated and angry they would feel in response to a situation would be associated with how they judged the behaviors of others who were part of the situation. When our attributions about others' behaviors influence our emotional responses, it illustrates the attribution-emotion association theory. ${ }^{12,13}$ In non-TBI populations, attributions of intent, hostility and blame have been shown to predict anger ratings. ${ }^{12,14-17}$ In a first time examination of this association in the TBI population, we presented participants with moderate to severe TBI with hypothetical scenarios that described situations in which characters' actions in the story theoretically led 
to a negative outcome for the participant. After each scenario, the participant rated how angry they would be in response to the situation, as well as how intentional and hostile they thought the character's actions were, and whether or not they blamed the person for the negative outcome. The results revealed strong significant associations between participants’ anger ratings in response to the situation and their negative attributions. ${ }^{3}$ Thus, the more intentional, hostile and blameworthy the behaviors were perceived to be, the more elevated their anger ratings. The findings from this study led to the next critical research question - are people with TBI prone to judge others’ behaviors more harshly than are healthy controls, especially when behaviors are ambiguous or even benign?

A tendency to make distorted judgments about others' behaviors (that is, judgments that are significantly more negative than those of the general population and/ or disproportionate to the action) is referred to as negative attribution bias. ${ }^{18,19}$ Negative attribution bias is a clinical problem that has been identified in people with schizophrenia, aggressive children and adults, and abusive spouses. ${ }^{20-23}$ Not surprisingly, negative attribution bias has been associated with exaggerated anger in response to situations, as well as trait aggression and aggressive behavior. ${ }^{21,24}$ Furthermore some evidence suggests these biases in nonTBI populations are the result of cognitive distortions, poor social cognition, and impaired problem solving. ${ }^{21,24-26}$ This knowledge has been used to develop interventions that have been shown to reduce negative attribution bias in adolescent offenders and aggressive children. ${ }^{27-29}$ Given that cognitive distortions and impaired social cognition are both common sequelae of $\mathrm{TBI}^{2,18,30-32}$, there is an obvious potential risk for this population to develop negative attribution bias. Thus, the main aim of this study was to examine this bias by comparing the negative attributions that people with and without TBI assign to other's behaviors. The second aim was to evaluate the degree to which these negative attributions predict participants' ratings of feeling irritated and angry. Although anger has been the primary focus thus far, we also included "irritated” as an option to capture feelings that are not quite as intense as anger, but can also affect behavior. We hypothesized 
that the negative attribution ratings of participants with TBI would be significantly higher than those of healthy controls, and that negative attribution ratings would predict their self-ratings of being irritated and angry in response to the scenarios.

\section{METHODS}

\section{Participants}

We recruited a sample of 49 healthy controls who were age and gender frequency matched with an earlier sample of 46 participants with TBI described in a previous study. ${ }^{3}$ The ethics review board approved this study and all participants provided consent before participating. Participants with TBI were recruited through letters sent to current and former patients of a local rehabilitation hospital; flyers were posted in the hospital's outpatient clinic and were circulated to participants receiving vocational rehabilitation services related to their TBI; and recruitment materials were also distributed to local brain injury support groups. Healthy controls were recruited from local research study advertisements (e.g., University website; Craigslist).

Participants had to be between 18 and 75 years old. People with TBI had to have sustained a moderate to severe TBI at least three months prior to the study. ${ }^{33}$ TBI and injury severity were indicated by at least one of the following: Glasgow Coma Scale score ( $<13$ at the time of injury), post-traumatic amnesia ( $\geq 24$ hours), loss of consciousness ( $\geq 30$ minutes), or abnormal neuroimaging consistent with moderate to severe brain injury. This information was initially obtained via self or family report for screening and was later confirmed via patient medical records, when available (i.e., for $83 \%$ of the participants). In addition, participants with TBI had to demonstrate comprehension sufficient to pass a screening measure. ${ }^{34}$ Participants with TBI were excluded if they had a pre-morbid acquired brain injury (e.g., stroke; anoxia), neurological disorder (e.g., autism; Alzheimer’s), or major psychiatric disorder (e.g., schizophrenia, bipolar disorder). Healthy control participants were excluded if they had ever been diagnosed with a neurological injury or disorder (e.g., 
acquired brain injury, stroke, Alzheimer’s) or major psychiatric disorder (e.g., schizophrenia, bipolar disorder). Refer to Table 1 for participant demographics and injury characteristics.

\section{Measures}

Comprehension Assessment (Screening). Sufficient comprehension was an inclusion criterion since the main component of the study required participants to read scenarios (described below). Comprehension was evaluated with an abbreviated version of the Discourse Comprehension Test (DCT) ${ }^{34}$. Two DCT stories were administered, one to assess oral comprehension and the other to assess written comprehension. Participants had to achieve at least $75 \%$ correct on either the oral or written story since hypothetical scenarios were available in both formats and delivered to the participant in the format for which they had the better comprehension score.

Hypothetical Scenarios and Irritated, Angry and Attribution Ratings: Twenty-one scenarios ${ }^{24}$ that were previously validated described situations in which a character's actions in the story theoretically resulted in a negative outcome for the participant. Characters’ behaviors portrayed benign, ambiguous, or hostile actions (7 per condition). These scenarios were slightly modified from their original wording in order to reduce some grammatical complexity (without changing content). The final reading level of the modified stories ranged from grade 5.6-7.8. Scenarios were presented to participants visually and/ or orally on a computer (depending on DCT scores). After each scenario, participants rated how irritated and angry they were in response to the scenario and how much they believed the characters’ behaviors were intentional, hostile, and blameworthy (attribution ratings) using a 9-point Likert scale (1 represented not irritated, no anger, unintentional, not hostile, and not to blame; 9 represented extreme anger, completely intentional, hostile, and total blame).

\section{DATA ANALYSES}

Ratings for feeling irritated and angry and ratings for attributions of intent, hostility, and blame were individually averaged for each scenario type (benign, ambiguous, and hostile), creating 15 composite scores. 
For one participant, angry ratings and attribution scores were missing for two scenarios; therefore, we imputed these scores by calculating the participant's average attributions ratings from items within the same scenario type (1 ambiguous and 1 benign). Independent t-tests were calculated to determine group differences for negative attributions, irritated and anger ratings. The Holm-Bonferroni ${ }^{35}$ method was used to adjust for multiple comparisons. $d_{\text {Cohen }}$ was calculated to determine effect sizes between groups. Separate Spearman Rho correlations were calculated to determine the associations of anger ratings with attributions of intent, hostility, and blame ratings for each participant group. Furthermore, four multiple linear regressions (Enter method) were calculated separately for each of the participant groups to determine the amount of anger rating variance accounted for by negative attributions (hostile intent and blame) for benign, ambiguous, and hostile scenarios, as well as for the entire set of scenarios. Because intent and hostility ratings were so similar (rho=.891 and .890, $\mathrm{p}<.001$ for TBI and HC's, respectively), we averaged the ratings from both categories to create a composite "hostile intent" score for the individual scenario types and for the entire set. In order to conduct regression analyses for the entire set of scenarios, we summed the ratings for all scenario types (benign, ambiguous, hostile), and calculated global average scenario ratings for hostile intent, blame and anger ratings for people with and without TBI.

\section{RESULTS}

\section{Group Demographic Comparisons}

Our analyses indicated participant matching was successful: age $(\mathrm{t}=-.262, \mathrm{p}=.794)$, $\operatorname{sex}\left(\chi^{2}=.000\right.$ $\mathrm{p}=.996)$, and years of education ( $\mathrm{t}=-1.899, \mathrm{p}=.061)$ did not significantly differ between participants with and without TBI. Refer to Table 1 for descriptive statistics. For years of education, Levene’s test indicated unequal variances ( $F=5.237, \mathrm{p}=.024)$; thus, statistical values for 'equal variances not assumed' were used. 
Compared to healthy controls, participants with TBI rated characters’ behaviors as significantly more intentional, hostile, and blameworthy for benign, ambiguous, and hostile scenarios. Participants with TBI had significantly higher ratings for being irritated in response to benign and hostile scenarios than did healthy controls; no difference was found for the intensity of being irritated in response ambiguous scenarios. Ratings for feeling angry were significantly higher in participants with TBI compared to healthy controls for benign, ambiguous, and hostile scenario types. The Holm-Bonferroni ${ }^{35}$ method was also applied to determine significance after adjusting for multiple comparisons. Statistical values and significance outcomes after adjusting for multiple comparisons are provided in Table 2. Effect sizes ranged from .388-.801.

INSERT TABLE 2-

\section{Relations Between Ratings for Feeling Angry and Negative Attributions by Group}

Results from correlation and regression analyses are provided below and in Table 3. Since feeling irritated and angry ratings were so highly correlated (rho=.835, $\mathrm{p}<.001$ and rho=.837, $\mathrm{p}<.001$, respectively for TBI and healthy controls) and outcomes were similar for both, we only report results for anger ratings.

TBI Group. Average ratings for attributions of intent, hostility, and blame for the entire set of scenarios were significantly correlated with angry ratings (rho $=.829, .775, .683$, respectively; $\mathrm{p}<.001$ for all). This pattern was similar when calculated for individual scenario types: benign (rho=.666, .664, .625, respectively; $\mathrm{p}<.001$ for all); ambiguous (rho=.724, .686, .647, respectively; $\mathrm{p}<.001$ for all); and hostile (rho=.787, .793, .678 , respectively; $\mathrm{p}<.001$ for all). Four standard multiple linear regressions (using the Enter method) were calculated to determine how much of participants' angry ratings (in response to the scenarios) was accounted for by attributions of hostile intent and blame in the TBI group for each scenario type (benign, ambiguous, hostile), as well as the entire set of scenarios. The model significantly accounted for $58.4 \%, 62 \%, 75.1 \%$ and 72.4\% of the adjusted angry rating variance, for benign, ambiguous, hostile, and all scenarios, respectively. 
Tolerance and variance inflation (VIF) scores for both regressions indicated multicollinearity was not a problem.

Healthy Control Group. In the healthy control group, average ratings for attributions of intent, hostility, and blame for all scenarios were significantly correlated with angry ratings (rho $=.727, .784$, and .739, respectively; $\mathrm{p}<.001$ for all). Again, a similar pattern was identified for individual scenario types: benign (rho=.599, .665, and .656, respectively; $\mathrm{p}<.001$ for all); ambiguous (rho=.793, .820, and .763, respectively; $\mathrm{p}<.001$ for all); and hostile (rho=.733, .830, and .769, respectively; $\mathrm{p}<.001$ for all). The same regression procedure calculated for participants with TBI was repeated for HCs. The model accounted for 50.6\%, 68.1\%, $68.3 \%$ and $65.3 \%$ of the adjusted angry rating variance, for benign, ambiguous, hostile, and all scenarios, respectively. Again, multicollinearity was not a problem, as indicated by tolerance and variance inflation (VIF) scores for all regressions.

-INSERT TABLE 3

\section{DISCUSSION}

This study constitutes a preliminary comparison of how people with and without TBI judge others’ behaviors, and whether or not these judgments are associated with how irritated and angry they think they would feel in response to a particular situation. Our first hypothesis was that on average, people with TBI would judge others' behaviors more negatively than would healthy controls (negative attribution bias). Indeed, we found that participants with TBI rated characters’ behaviors as significantly more intentional, hostile and blameworthy than did participants without TBI, indicating a negative attribution bias in the former group. While both groups' attributions became increasingly more negative as the scenarios went from benign to hostile (Table 2), the attribution ratings of participants with TBI were significantly more negative than those of healthy controls, even when scenarios described ambiguous and benign behaviors. Although attributions of intent and hostility for benign and ambiguous scenarios could no longer be deemed significant after correcting 
for multiple comparisons, it can be argued based on the moderate effect sizes (.428-.505) that the findings are still noteworthy with this relatively small sample size. All blame attributions remained significant even after multiple comparisons.

Our second hypothesis was that negative attribution ratings would be significantly related to how irritated and angry participants would be in response to situations. Because feeling irritated and angry ratings were so highly correlated, we only report the relation between angry ratings and attribution ratings. The results from our correlational analyses suggested that participants’ angry ratings increased with more severe attribution ratings. In other words, the more intentionally hostile and blameworthy a participant believed the characters' actions to be, the stronger that participant's ratings were for feeling angry. Moreover, participants’ negative attribution ratings significantly predicted their angry ratings to the scenarios. This finding held for both participant groups and also when analyzed separately for each scenario type. This suggests that angry ratings are significantly predicted by attributions of hostile intent and blame regardless of whether the action is benign, ambiguous, or hostile.

It is important to note that these findings do not suggest that everyone with a TBI has a negative attribution bias. The effect sizes indicate that there is a subgroup of people with TBI who were more likely to judge others’ behaviors harshly. Many possible factors may be contributing to this bias in people with TBI (e.g., depression, anxiety, executive dysfunction, and/ or social inference impairments). However, as a preliminary study, the intention was not to understand why some people with TBI may have a negative attribution tendency, but rather to determine whether the bias exists within the TBI population and whether it may be relevant to their feelings of anger. With this preliminary evidence, the next step is to examine characteristics associated with a negative attribution tendency so that it can be determined who is at risk and ultimately identify factors that, if treated, may help reduce the bias. The observation that attribution ratings increased in the expected direction (i.e., ambiguous scenarios were rated more negatively than benign, and the 
hostile scenarios more negatively than the ambiguous scenarios) is a good indicator that people with TBI had adequate comprehension of the stories and were using the information from each scenario to make their judgments; in other words, their ratings were not random.

\section{Treatment Implications}

Negative attribution bias has never been the primary focus in evidence-based studies on anger and aggression treatments after TBI. However, it would be a mistake to assume that negative attributions have not in some way been peripherally addressed in studies that used a cognitive behavioral therapy (CBT) approach to treating anger and aggression in people with brain injury. CBT generally aims to reframe the maladaptive thoughts that a person has about oneself, others, or their surrounding environment, to reduce subsequent unpleasant emotional responses. ${ }^{18,36-38}$ Unjustified or unwarranted attributions of intent, hostility and blame are types of cognitive distortions; however, there are many others that are more commonly targeted (e.g., magnification, overgeneralization). ${ }^{39}$ Assuming CBT sessions generally start with a broader approach for identifying and reframing many types of maladaptive thoughts, it is uncertain to what degree the past studies using CBT helped participants restructure attributions of intent, hostility and blame. If future studies confirm that some people with TBI are at risk for negative attribution bias, researchers should then investigate the effectiveness of a targeted CBT approach concentrating on negative attributions of intent, hostility and blame in this subgroup. Also, future studies should examine factors that contribute to negative attribution bias. Such information can be used to construct a multi-component approach to treating anger associated with negative attribution bias.

\section{Limitations}

One limitation of this study is that scenarios were hypothetical and therefore the results may not accurately reflect participants' true attributions and anger in “real world” situations. While some negative attribution studies of other populations staged live situations of provocation ${ }^{40,41}$, it would be difficult to 
ethically justify this type of manipulation in people with TBI. Another limitation is that we did not inquire about potential behavioral responses to the hypothetical situations. Understanding how participants’ attributions and anger ultimately affects their behavior is an important variable that should not be ignored. If people respond appropriately despite having distorted negative attributions about others' behaviors, it may be less clinically concerning. Another study limitation is that we were unable to evaluate potential correlates with negative attribution bias due to the relatively small sample size of the study; consequently, we cannot yet comment on factors that are correlated with or predict this bias in people with TBI. Other studies in non-TBI populations indicate that negative attributions are associated with poor social cognition and problem solving, which has been used to inform treatment approaches in their populations. ${ }^{27,28}$ It will be important in future studies to examine correlations with these variables and other potential predictors (e.g., depression, anxiety) in people with TBI. A more comprehensive understanding of the factors that contribute to negative attribution bias can guide clinicians in formulating more effective interventions that extend beyond general CBT.

\section{CONCLUSION}

This preliminary study suggests that some people with TBI may have negative attribution biases about others' behaviors, which may contribute to their anger. The attributions of intent, hostility and blame ratings observed in this study indicate that, for some people with TBI, innocent situations do not appear as benign as they do to people without a TBI; when actions may be a bit ambiguous, some TBI survivors may be less likely to give the benefit of the doubt. However, these preliminary findings should be interpreted with caution due to the small sample size and the fact that it represents a sample of people who are many years post-injury. Future studies with a larger sample size should be conducted to replicate these findings as well as to begin to identify factors that put people with TBI at risk for having a negative attribution bias. If additional research provides further evidence for negative attribution bias after TBI, the possibility of regularly testing for negative attributions of intent, hostility and blame in patients with TBI who present with anger and aggression should be 
considered. This body of work could be critical for identifying people with negative attribution bias and enhancing treatment approaches for better management of anger and aggression after TBI.

\section{References}

1. Demark J, Gemeinhardt M. Anger and it s management for survivors of acquired brain injury. Brain Injury. 2002;16(2):91-108. 
2. Hart T, Vaccaro MJ, Hays C, Maiuro RD. Anger self-management training for people with traumatic brain injury: a preliminary investigation. The Journal of head trauma rehabilitation.

2012;27(2):113-122.

3. Neumann D, Malec JF, Hammond FM. The association of negative attributions with irritation and anger after brain injury. Rehabilitation psychology. 2015;60(2):155.

4. Walker AJ, Nott MT, Doyle M, Onus M, McCarthy K, Baguley IJ. Effectiveness of a group anger management programme after severe traumatic brain injury. Brain Injury. 2010;24(3):517-524.

5. Winegardner J, Keohane C, Prince La, Neumann D. Perspective training to treat anger problems after brain injury: Two case studies. NeuroRehabilitation. Submitted for review November 2015.

6. Neumann D, Malec JF, Hammond FM. The relationship of aggression with alexithymia, depression, and anxiety after traumatic brain injury. Journal of Head Trauma Rehabilitation Under Review, October 2015.

7. Baguley IJ, Cooper, J., and Felmingham, K. Aggressive behavior following traumatic brain injury How Common Is Common? Journal of Head Trauma Rehabilitation. 2006;21(1):45-56.

8. Kim E, Lauterbach EC, Reeve A, et al. Neuropsychiatric Complications of Traumatic Brain Injury. The Journal of Neuropsychiatry and Clinical Neurosciences. 2007;19(2):106-127.

9. Tateno A, Jorge RE, Robinson RG. Clinical correlates of aggressive behavior after traumatic brain injury. The Journal of neuropsychiatry and clinical neurosciences. 2003;15(2):155-160.

10. Wood RL, Liossi C, Wood L. The impact of head injury neurobehavioural sequelae on personal relationships: preliminary findings. Brain Inj. 2005;19(10):845-851.

11. Averill J. Studies on anger and aggression. Implications for theories of emotion. The American psychologist. 1983;38(11):1145-1160.

12. Fincham FD, Bradbury TN. Assessing attributions in marriage: The relationship attribution measure. Journal of Personality and Social Psychology. 1992;62(3):457-468.

13. Kelley HH, Michela JL. Attribution theory and research. Annual review of psychology. 1980;31(1):457-501.

14. Ellsworth PC, Scherer KR. Appraisal processes in emotion. Handbook of affective sciences. 2003:572-595.

15. Sanford K. Attributions and anger in early marriage: Wives are event-dependent and husbands are schematic. Journal of Family Psychology. 2005;19(2):180-188.

16. Scherer KR. Appraisal considered as a process of multilevel sequential checking. Appraisal processes in emotion: Theory, methods, research. 2001;92:120.

17. Smith CA, Kirby LD. Appraisal as a pervasive determinant of anger. Emotion. 2004;4(2):133-138.

18. Beck R, Fernandez E. Cognitive-behavioral therapy in the treatment of anger: A meta-analysis. Cognitive Therapy and Research. 1998;22(1):63-74.

19. Kassinove H, Sukhodolsky DG. Anger disorders: Basic science and practice issues. Issues in comprehensive pediatric nursing. 1995;18(3):173-205.

20. An SK, Kang JI, Park JY, Kim KR, Lee SY, Lee E. Attribution bias in ultra-high risk for psychosis and first-episode schizophrenia. Schizophrenia research. 2010;118(1):54-61.

21. Dodge KA. Translational science in action: Hostile attributional style and the development of aggressive behavior problems. Development and psychopathology. 2006;18(03):791-814.

22. Holtzworth-Munroe A, Rehman U, Herron K. General and spouse-specific anger and hostility in subtypes of maritally violent men and nonviolent men*. Behavior Therapy. 2000;31(4):603-630.

23. Holtzworth-Munroe A, Smutzler N. Comparing the emotional reactions and behavioral intentions of violent and nonviolent husbands to aggressive, distressed, and other wife behaviors. Violence and Victims. 1996;11(4):319-339. 
24. Epps J, Kendall PC. Hostile attributional bias in adults. Cognitive Therapy and Research. 1995;19(2):159-178.

25. Bailey CA, Ostrov JM. Differentiating forms and functions of aggression in emerging adults: Associations with hostile attribution biases and normative beliefs. Journal of Youth and Adolescence. 2008;37(6):713-722.

26. Jeon IH, Kim KR, Kim HH, et al. Attributional Style in Healthy Persons: Its Association with'Theory of Mind'Skills. Psychiatry investigation. 2013;10(1):34-40.

27. Group CPPR. Using the Fast Track randomized prevention trial to test the early-starter model of the development of serious conduct problems. Development and Psychopathology. 2002;14(4):925.

28. Guerra NG, Slaby RG. Cognitive mediators of aggression in adolescent offenders: II. Intervention. Developmental Psychology. 1990;26(2):269.

29. Sukhodolsky DG, Golub A, Stone EC, Orban L. Dismantling Anger Control Training for Children: A Randomized Pilot Study of Social Problem-Solving Versus Social Skills Training Components. Behavior Therapy. 2005;36(1):15-23.

30. Alderman N. Contemporary approaches to the management of irritability and aggression following traumatic brain injury. Neuropsychological Rehabilitation. 2003;13(1):211-240.

31. McDonald S, Flanagan S. Social perception deficits after traumatic brain injury: Interaction between emotion recognition, mentalizing ability, and social communication. Neuropsychology. 2004;18(3):572-579.

32. McDonald S, Flanagar S, Rollins J, Kinch J. A new clinical tool for assessing social perception after traumatic brain injury. Journal of Head Trauma Rehabilitation. 2003;18(3):219-238.

33. Malec JF, Brown AW, Leibson CL, et al. The Mayo classification system for traumatic brain injury severity. Journal of Neurotrauma. 2007;24(9):1417-1424.

34. Brookshire R, Nicholas L. Discourse comprehension test. Tucson, AZ: Communication Skill Builders. 1993:105-108.

35. Holm S. A simple sequentially rejective multiple test procedure. Scandinavian journal of statistics. 1979:65-70.

36. Beck A, Rush A, Shaw B, Emery G. Cognitive therapy of depression. New York. Guilford Press; 1979.

37. Bradbury C, Christensen B, Lau M, Ruttan L, Arundine A, Green R. The efficacy of cognitive behavior therapy in the treatment of emotional distress after acquired brain injury. Archives of physical medicine and rehabilitation. 2008;89(12 Suppl):S61.

38. Salkovskis PM. Frontiers of cognitive therapy. Guilford Press; 1997.

39. Gilbert P. The evolved basis and adaptive functions of cognitive distortions. The British journal of medical psychology. 1998;71:447.

40. Dodge KA. Social cognition and children's aggressive behavior. Child development. 1980:162-170.

41. Steinberg MS, Dodge KA. Attributional bias in aggressive adolescent boys and girls. Journal of Social and Clinical Psychology. 1983;1(4):312-321.

Table 1. Demographic and injury related information 


\begin{tabular}{|c|c|c|}
\hline Characteristic & $\begin{array}{c}\text { TBI }(\mathrm{n}=46) \\
\text { Mean (SD)/Frequency (\%) }\end{array}$ & $\begin{array}{l}\text { Healthy Controls (n=49) } \\
\text { Mean (SD)/Frequency (\%) }\end{array}$ \\
\hline Age & $42.28(14.42)$ & $43.04(13.75)$ \\
\hline $\begin{array}{r}\text { Gender } \\
\text { Male }\end{array}$ & $67.4 \%$ & $67.3 \%$ \\
\hline Race/Ethnicity & $\begin{array}{c}91.3 \% \\
4.3 \% \\
4.3 \% \\
\end{array}$ & $\begin{array}{c}71.4 \% \\
8.2 \% \\
18.4 \% \\
\end{array}$ \\
\hline Education (Years) & $14.78(2.55)$ & $15.67(1.89)$ \\
\hline $\begin{array}{l}\text { Cause of Injury } \\
\text { Motor Vehicle Accident } \\
\text { Fall } \\
\text { Assault } \\
\text { Other }\end{array}$ & $\begin{array}{c}58.7 \% \\
19.6 \% \\
2.2 \% \\
19.86 \% \\
\end{array}$ & \\
\hline Months post-injury & $58.40(61.32)$ & \\
\hline GCS, Medical Records $(n=29)$ & $9.83(2.94 ; 3-15)$ & \\
\hline $\begin{array}{r}\text { LOC, days } \\
\text { Self-report }(n=34) \\
\text { Medical Records }(n=19)\end{array}$ & $\begin{array}{l}14.75(21.25 ; 0-90) \\
9.1053(6.05 ; 0-16) \\
\end{array}$ & \\
\hline Self-report PTA, days $(n=21)$ & 26.63 (39.50; 2-180) & \\
\hline $\begin{array}{l}\text { Abnormal neuroimaging } \\
\text { results ( } \mathrm{n}=38 \text { ) (yes) } \\
\text { e.g., (Hematoma, Hemorrhage, } \\
\text { Contusions, Diffuse Axonal } \\
\text { Injury) }\end{array}$ & $92 \%$ & \\
\hline
\end{tabular}

Table 2. Irritated, anger and attribution ratings. *Indicates items that remained significant after applying the Holm-Bonferroni ${ }^{35}$ method to adjust for multiple comparisons. 


\begin{tabular}{|c|c|c|c|}
\hline & $\begin{array}{c}\text { TBI } \\
\text { Means (S.D.) }\end{array}$ & $\begin{array}{c}\text { HC } \\
\text { Means (S.D.) }\end{array}$ & $\begin{array}{l}\text { Group differences } \\
\text { (Effect size, } \boldsymbol{d}_{\text {Cohen }} \text { ) }\end{array}$ \\
\hline \multicolumn{4}{|l|}{ Attributions of Intent } \\
\hline Benign Scenarios & $4.12(1.51)$ & $3.36(1.31)$ & $\mathrm{t}=2.65, \mathrm{p}=.010$ \\
\hline Ambiguous Scenarios & $5.01(1.99)$ & $4.19(1.51)$ & $\mathrm{t}=2.51, \mathrm{p}=.014(.469)$ \\
\hline Hostile Scenarios & $5.55(1.74)$ & $4.54(1.61)$ & $\mathrm{t}=2.94, \mathrm{p}=.004(.603)^{*}$ \\
\hline \multicolumn{4}{|l|}{ Attributions of Hostility } \\
\hline Benign Scenarios & 3.45 (1.79) & $2.75(1.48)$ & $\mathrm{t}=2.09, \mathrm{p}=.039(.428)$ \\
\hline Ambiguous Scenarios & $4.39(1.72)$ & $3.56(1.57)$ & $\mathrm{t}=2.45, \mathrm{p}=.016(.505)$ \\
\hline Hostile Scenarios & $4.90(1.85)$ & 3.78 (1.69) & $\mathrm{t}=3.08, \mathrm{p}=.003(.633)^{*}$ \\
\hline \multicolumn{4}{|l|}{ Attributions of Blame } \\
\hline Benign Scenarios & $5.61(1.74)$ & $4.31(1.67)$ & $\mathrm{t}=3.73, \mathrm{p}<.001(.762)^{*}$ \\
\hline Ambiguous Scenarios & $5.77(1.91)$ & $4.69(1.67)$ & $\mathrm{t}=2.93, \mathrm{p}=.004(.603)^{*}$ \\
\hline Hostile Scenarios & $5.98(1.64)$ & $4.96(1.73)$ & $\mathrm{t}=2.96, \mathrm{p}=.004(.605)^{*}$ \\
\hline \multicolumn{4}{|l|}{ Irritation Ratings } \\
\hline Benign Scenarios & $6.17(1.80)$ & $5.47(1.58)$ & $\mathrm{t}=2.03, \mathrm{p}=.045(.414)$ \\
\hline Ambiguous Scenarios & $6.04(1.79)$ & $5.38(1.61)$ & $\mathrm{t}=1.88, \mathrm{p}=.064(.388)$ \\
\hline Hostile Scenarios & $6.07(1.78)$ & $5.00(1.64)$ & $\mathrm{t}=3.03, \mathrm{p}=.003(.626)^{*}$ \\
\hline \multicolumn{4}{|l|}{ Anger Ratings } \\
\hline Benign Scenarios & $5.26(2.03)$ & $4.26(1.71)$ & $\mathrm{t}=2.59, \mathrm{p}=.011(.535)$ \\
\hline Ambiguous Scenarios & $5.18(1.99)$ & $4.10(1.70)$ & $\mathrm{t}=2.85, \mathrm{p}=.005(.585)^{*}$ \\
\hline Hostile Scenarios & $5.29(2.00)$ & $3.95(1.57)$ & $\mathrm{t}=3.65, \mathrm{p}<.001(.751)^{*}$ \\
\hline
\end{tabular}

Table 3. Predictors of anger ratings in response to scenarios in people with TBI and Healthy Controls. Model by scenario type with respective anger ratings as the dependent variable (DV). 
Negative attribution bias, TBI 18

\begin{tabular}{|c|c|c|c|c|c|c|c|c|c|c|c|}
\hline \multirow{2}{*}{$\begin{array}{c}\text { Anger } \\
\text { Ratings }=D V\end{array}$} & \multirow[t]{2}{*}{$\mathbf{R}$} & \multirow[t]{2}{*}{$\mathbf{R}^{2}$} & \multirow{2}{*}{$\begin{array}{c}\text { Adjusted } \\
\mathbf{R}^{2}\end{array}$} & \multirow[t]{2}{*}{$\mathbf{F}$} & \multirow[t]{2}{*}{ Sig } & \multirow[t]{2}{*}{ Beta } & \multirow[t]{2}{*}{$\mathbf{t}$} & \multirow[t]{2}{*}{ Sig } & \multirow{2}{*}{$\begin{array}{c}\text { Part } \\
\text { Correlations } \\
\end{array}$} & \multicolumn{2}{|c|}{ Collinearity } \\
\hline & & & & & & & & & & Tolerance & VIF \\
\hline $\begin{array}{l}\text { Benign } \\
\text { (TBI) } \\
\text { Hostile Intent } \\
\text { Blame }\end{array}$ & .776 & .602 & .584 & 32.55 & $<.001$ & $\begin{array}{l}.425 \\
.412\end{array}$ & $\begin{array}{l}.762 \\
3.07 \\
2.97\end{array}$ & $\begin{array}{l}.450 \\
.004 \\
.005\end{array}$ & $\begin{array}{l}.295 \\
.286\end{array}$ & $\begin{array}{l}.481 \\
.481\end{array}$ & $\begin{array}{l}2.077 \\
2.077\end{array}$ \\
\hline $\begin{array}{l}\text { Benign } \\
\text { (HC) } \\
\text { Hostile Intent } \\
\text { Blame }\end{array}$ & .725 & .526 & .506 & 25.55 & $<.001$ & $\begin{array}{l}.360 \\
.426\end{array}$ & $\begin{array}{c}2.0 \\
2.53 \\
2.99\end{array}$ & $\begin{array}{l}.052 \\
.015 \\
.005\end{array}$ & $\begin{array}{l}.256 \\
.303\end{array}$ & $\begin{array}{l}.507 \\
.507\end{array}$ & $\begin{array}{l}1.97 \\
1.97\end{array}$ \\
\hline $\begin{array}{l}\text { Ambiguous } \\
\text { (TBI) } \\
\text { Hostile Intent } \\
\text { Blame }\end{array}$ & .798 & .637 & .620 & 37.75 & $<.001$ & $\begin{array}{l}.619 \\
.218\end{array}$ & $\begin{array}{l}.617 \\
4.36 \\
1.54\end{array}$ & $\begin{array}{c}.541 \\
<.001 \\
.132\end{array}$ & $\begin{array}{l}.400 \\
.141\end{array}$ & $\begin{array}{l}.418 \\
.418\end{array}$ & $\begin{array}{l}2.39 \\
2.39\end{array}$ \\
\hline $\begin{array}{l}\text { Ambiguous } \\
\text { (HC) } \\
\text { Hostile Intent } \\
\text { Blame }\end{array}$ & .833 & .694 & .681 & 52.12 & $<.001$ & $\begin{array}{l}.591 \\
.270\end{array}$ & $\begin{array}{l}.551 \\
3.77 \\
1.72\end{array}$ & $\begin{array}{c}.584 \\
<.001 \\
.092\end{array}$ & $\begin{array}{l}.308 \\
.140\end{array}$ & $\begin{array}{l}.271 \\
.271\end{array}$ & $\begin{array}{l}3.69 \\
3.69\end{array}$ \\
\hline $\begin{array}{l}\text { Hostile } \\
\text { (TBI) } \\
\text { Hostile Intent } \\
\text { Blame }\end{array}$ & .872 & .762 & .751 & 68.99 & $<.001$ & $\begin{array}{l}, 659 \\
.272\end{array}$ & $\begin{array}{l}-1.1 \\
6.22 \\
2.56\end{array}$ & $\begin{array}{l}.278 \\
<.001 \\
.014\end{array}$ & $\begin{array}{l}.462 \\
.190\end{array}$ & $\begin{array}{l}.492 \\
.492\end{array}$ & $\begin{array}{l}2.03 \\
2.03\end{array}$ \\
\hline $\begin{array}{l}\text { Hostile } \\
\text { (HC) } \\
\text { Hostile Intent } \\
\text { Blame }\end{array}$ & .834 & .696 & .683 & 52.65 & $<.001$ & $\begin{array}{l}.433 \\
.434 \\
\end{array}$ & $\begin{array}{l}.659 \\
2.81 \\
2.82\end{array}$ & $\begin{array}{l}.513 \\
.007 \\
.007\end{array}$ & $\begin{array}{l}.228 \\
.229 \\
\end{array}$ & $\begin{array}{l}.278 \\
.278 \\
\end{array}$ & $\begin{array}{l}3.6 \\
3.6 \\
\end{array}$ \\
\hline $\begin{array}{l}\text { Overall } \\
\text { Scenarios } \\
\text { (TBI) } \\
\text { Hostile Intent } \\
\text { Blame }\end{array}$ & .858 & .736 & .724 & 60.04 & $<.001$ & $\begin{array}{l}.649 \\
.247\end{array}$ & $\begin{array}{l}5.10 \\
1.94\end{array}$ & $\begin{array}{l}<.001 \\
.059\end{array}$ & $\begin{array}{l}.399 \\
.152\end{array}$ & $\begin{array}{l}.378 \\
.378\end{array}$ & $\begin{array}{l}2.65 \\
2.65\end{array}$ \\
\hline $\begin{array}{l}\text { Overall } \\
\text { Scenarios } \\
\text { (HC) } \\
\text { Hostile Intent } \\
\text { Blame }\end{array}$ & .817 & .667 & .653 & 46.11 & $<.001$ & $\begin{array}{l}.496 \\
.353\end{array}$ & $\begin{array}{l}3.12 \\
2.22\end{array}$ & $\begin{array}{l}.003 \\
.031\end{array}$ & $\begin{array}{l}.265 \\
.189\end{array}$ & $\begin{array}{l}.286 \\
.286\end{array}$ & $\begin{array}{l}3.50 \\
3.50\end{array}$ \\
\hline
\end{tabular}

